\title{
A Wholegrain Level Dry Separation System for Thermal Coal Sorting Analysis
}

\author{
Chao Wang ${ }^{1, \text { a }}$, Jinbo Zhu ${ }^{1, \text { b }}$, Erning Zhao ${ }^{2, \mathrm{c}}$ \\ ${ }^{1}$ Materials science and engineering, Anhui University of Science \& Technology, \\ Huainan, 232001, China \\ ${ }^{2}$ Economics and Management, Anhui University of Science \& Technology, \\ Huainan, 232001, China \\ aawangchao1987wc@163.com, boppooppo5@163.com, czhaoerning1990@126.com
}

Keywords: Thermal coal, Wholegrain, Dry separation system, Strategy change, Ideal coal size-grading

\begin{abstract}
This paper presents a dry separation system for thermal coal sorting in which the major grading equipment don't need to water, to avoid the shortage of the traditional wet separation process along with the complex slime water treatment systems, simplifying the process, and reducing the costs, meeting the environments require for the western and northern of China where rich coal but less water. The dry coal preparation system proposed the ideal coal size-grading, $6 \mathrm{~mm}$ granularity points, for the dry separation system of thermal coal, based on the size requirements, $6 \sim$ $50 \mathrm{~mm}$, of dry separation equipment for the efficient separation and the requirements size, $<6 \mathrm{~mm}$, of the circulating fluidized bed boilers for power generation, to ensure that the system can run efficiently in order to promote the strategy change from transporting coal to transmitting electricity.
\end{abstract}

\section{Introduction}

In China, thermal coal mainly stored in the western and northern regions, especially in the north and northwest regions including $80 \%$ of coal reserves and accounting for $62 \%$ of the country's total coal reserves, but in East China, the Industry developed regions, only $1.73 \%$ of the country's thermal coal reserves, and in northeast and south-central regions, the total thermal coal reserves were also less than 3\%. According to the distribution of thermal coal in China, the focus of washing and processing of thermal coal is bound to shift to the west and north regions. While wet coal cleaning process becomes less realistic in the western arid northern regions due to less water, and dry cleaning technique has been widely promoted and applied due to water less, simple process and eliminating the need for water and follow-up of complex slime water treatment process in the wet coal preparation, which reduces costs, reduces sewage discharge, and protects the environment in recent years [1].

With the increased degree of mechanization of coal mining, fine coal in the raw coal also increased, especially the less-than $6 \mathrm{~mm}$ particle size class which even more than $50 \%$, while mostly low-rank bituminous coals, long-flame coal, not caking coal, weakly caking coal, 1/2-caking coal, stored in the western China, the biggest feature of the low-rank bituminous coals is low ash, low sulfur, and the ash was generally below $15 \%$, and the sulfur was generally less than $1 \%$, so the coal quality meets the basic quality requirements of power generation coal, and can be used in the thermal coal power plants directly [2].

As coal production increases and coal production - transport - pin pattern shapes into form, coal shipped from north to south and east to west China will bring the issue of transport costs, lack of capacity, etc., thereby constraining the development of coal processing. Therefore, the construction of large-sized pithead power plants and the change of coal for power transmission are inevitable in the long term. Academician Qing-Ru Chen, an academician, proposed that dry separation technology should be used to build large-sized heat - electricity generation power plants, which is an important strategy for energy sustainable development in China [3]. 
In the dry coal preparation system, the row coal was graded firstly, then fine coal power plants can be used for power generation directly, while the larger particles are carried to destination after dry grading and separation, so the system achieved full grain size grading of coal and dry separation, looking forward to promoting the strategic transformation that coal is translated into electricity for transportation.

\section{Selection of Core Separation Equipment}

The main equipment of the dry coal preparation system include: pre-grading sieve, crusher, vibrating screen classifier, spiral wind screen off powder grader, dry separator, air dense medium fluidized bed, high pressure blower, dust collection device, circulating fluidized bed furnace. The selection of the core equipment, spiral wind screen off powder grader, dry separator, air dense medium fluidized bed and circulating fluidized bed furnace, are essential for the efficient operation of the system.

Spiral Wind Screen off Powder Grader. The material classification be enhanced by the combined effect of the transported spiral centrifugal force and airflow during descent in the screen surface, while the secondary reinforcement grading was supplied by using tangential rotary flow injection, So the screen blinding issue was solved fundamentally which is usually highlighted in bohou sieve, flip-flow screen, etc, to realize the arbitrarily adjustment of the grading granularity from $0 \sim 13 \mathrm{~mm}$ based on the requirements. In this system the spiral wind screen off powder grader grades the coal at the $6 \mathrm{~mm}$ granular level.

Dry Separator. Using CFX-type differential wind dry sorter. The effective separation size of the separator is $50 \sim 0 \mathrm{~mm}$, and its sorting efficiency up to $86 \%$, while increasing by $10 \%$ to $30 \%$ less than similar products in processing capacity, but reducing the energy consumption by $50 \%$ to $63 \%$. Meanwhile the device runs with not water, so suiting the lack of water area [5-6].

Air Dense Medium Fluidized Bed. The effective separation size of the equipment is $50 \sim 6 \mathrm{~mm}$, the fluidized technology is used in the field as a new efficient dry separation technology, its separation media is solid-gas flow with high precision and its production process does not require water, coupling with no environmental pollution and low operating costs [7-8].

Circulating Fluidized Bed Furnace. The coal-feed size of the equipment is $8 \sim 0 \mathrm{~mm}$, and the furnace is an efficient and low-pollution clean-burning equipment, used for high-efficiency coal-fired power technology, which has a good applications in the thermal power plant in China in recent years.

\section{Separation Process}

The process flow diagram of the wholegrain level dry separation system for thermal coal sorting is showed in Fig. 1.

(1). First the raw coal is pre-sieved in the pre-grading sieve aiming at screening out chunks in the feed materials for the next selective crushing, and the undersize fine material will be graded again in the next step. The aperture of pre-grading sieve is set to $50 \mathrm{~mm}$.

(2). The oversize product of pre-grading sieve is feed into the double toothed roll crusher for crushing. After crushing, the material back to the pre-grading sieve for circulation.

(3). The undersize product of pre-grading sieve will be feed into the vibration sizing screen for classification operations. By practices that dry separator separation material has a certain lower limit of particle size. If the particle size is too small, the separating efficiency of dry separator will be seriously affected and therefore the feed of the dry separator need to be pre-graded for the appropriate size in order to improve the separation efficiency of the dry separator. Under the condition of the existing machinery, the vibration sizing screen has a high screening efficiency in 13 mm granular.

(4). The undersize products of vibration sizing screen are feed into spiral wind screen off powder grader for the next classification, the dry classifier requires a narrow range for feed size, generally as less than $13 \mathrm{~mm}$ granular, so that the particle size materials can be chosen within the scope of 
any grading granularity and be classified efficiently. Because of the size requirements of dry separation equipment for efficient separation is $50 \sim 6 \mathrm{~mm}$ granular, meanwhile the top size requirements of circulating fluidized bed boiler is $6 \mathrm{~mm}$ granular, so $6 \mathrm{~mm}$ granular is Selected as the ideal size for grading.

(5). The coarse particles, $13 \sim 6 \mathrm{~mm}$ granular, graded from spiral wind screen off powder grader, and the oversize product of vibration on the screen, $50 \sim 13 \mathrm{~mm}$ granular, are mixed into the cyclic dense medium fluidized bed. After separated, the clean coal and gangue products are obtained. The coal can be used as a product for sale, or as the feed to circulating fluidized bed furnace after broken, which is necessary for power generation, so the system can be adjusted according to the actual demand flexibly.

(6). The fine particles, graded from spiral wind screen off powder grader and satisfy the ash content requirements, can be feed directly into the circulating fluidized bed furnace for power generation. If do not meet the requirement, the fine particles can be provided in CFX type dry separator on separation, the clean coal, separated by CFX type dry separator separation can be used as the feed for the circulating fluidized bed furnace for the power generation.

(7). The gangues produced from Air dense medium fluidized bed and CFX dry separator of waste are mixed as the final waste product which can be used for mine backfilling, reducing environmental pollution.

(8). The system adopts high pressure fan to provide airflow for CFX dry separator, spiral wind screen off powder classifier for wind and air dense medium fluidized bed through independent air supply system, ensuring the power of sorting and grading.

(9). The air flow containing pulverized fuel ash produced by CFX dry separator, spiral wind screen off powder classifier and air dense medium fluidized bed can be collected into the bag filter through separate exhaust system by using the high pressure blower. Then the airflow without pulverized fuel ash will be discharged into atmosphere, avoiding the air pollution.

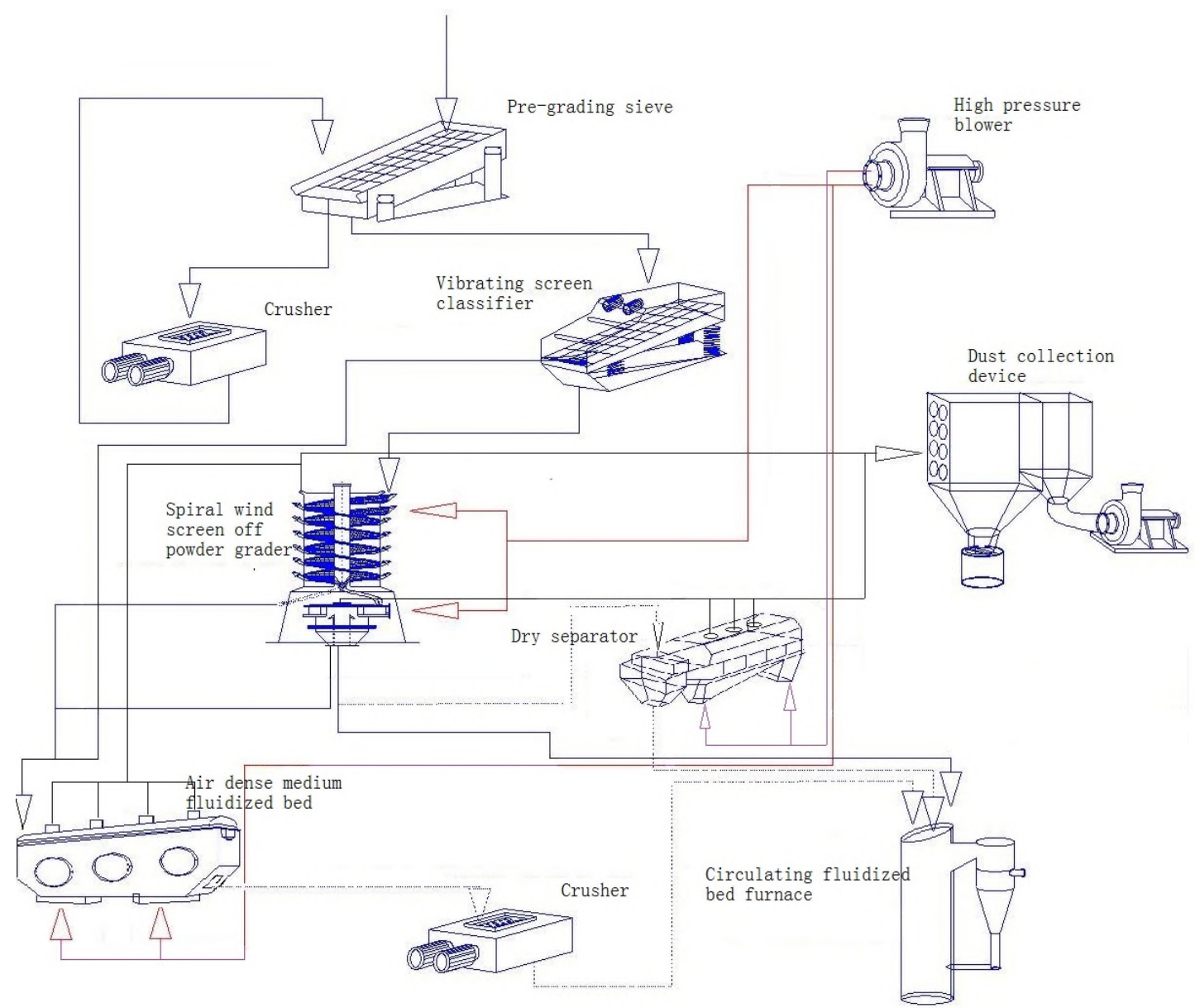

Fig. 1 Process flow diagram of the dry separation system for thermal coal sorting. 


\section{Conclusion}

The main classification and sorting equipment in this system don't need to water, avoiding the traditional wet separation process along with the complex slime water treatment systems and reducing the costs. So it adapts to be used in the north and west of China where lack of water, but rich in coal, which meets the strategy requirement of transporting coal from north to south and from west to east.

The particles separated from this system less than $6 \mathrm{~mm}$ have good quality and can be directly into the circulating fluidized bed furnace for power generation. The particles don't need to be separated, so it improves the separation ratio of coal indirectly, and alleviates the pressure of the shortage of China coal transport capacity. The particles greater than $6 \mathrm{~mm}$ can be separated in the system of efficient separation of coal and then used for power generation or used in other industrial production.

Spiral wind screen off powder grader in this system uses rotating air classification, which improves the efficiency of classification fundamentally and solves mesh clogging problem of the traditional grading equipment. So the system can adjust the grading granularity from $13 \sim 0 \mathrm{~mm}$ according to the need of any regulation to meet the granular need of dry separator and Air Dense Medium Fluidized Bed meanwhile ensure that the granular need of circulating fluidized bed furnace in pithead power plant, promoting the strategic transformation from transporting coal to transmitting electricity.

\section{Acknowledgement}

In this paper, the research was sponsored by the NSFC (Natural Science Foundation of China (Project No. 51374015)).

\section{References}

[1] S. Mohanta, S. Chakraborty, B. C. Meikap. Influence of Coal Feed Size on the Performance of Air Dense Medium Fluidized Bed Separator Used for Coal Beneficiation. Am. Chem. Soc. 50(18) (2011) 10865-10871.

[2] Z. F. Luo, J. F. Zhu, M. M. Fan, Y. M. Zhao, X. X. Tao. Low Density Dry Coal Beneficiation Using an Air Dense Medium Fluidized Bed. J. China U. Mining Technol. 17(3) (2007) 306-309.

[3] C. J. Du, N. X. Sun. Significance of dry coal preparation in Western China. Value Eng. 28(24) (2010) 44-45.

[4] Y. M. Xing. Some promotion suggestions of dry coal preparation technology in Western China. J. China coal. 31(3) (2005) 70-71.

[5] G. H. Yang, Y. M. Zhao, Q. G. Chen. Research of air classification associated with air dense medium fluidized bed separation technology. J. China U. Mining. 31(6) (2002) 596-604.

[6] D. W. Ye. In 2006, the survey of China coal preparation and coal quality. Coal Preparation Technol. 34(4) (2007) 1-5.

[7] G. M. Li, Y. S. Yang. Application of compound dry coal preparation technology in China. Coal P. Compr. Utilization. 23(5) (2006) 33-37.

[8] L. W. Xue, S. J. Jin. Application of FGX - 48 type compound dry coal preparation equipment in coal preparation plant of HanGu Village. Inner Mongolia Sci. Technol. Econ. 27(21) (2010) 114-118. 